\title{
Traffic Safety of the Trucking Industry in Saudi Arabia
}

\author{
Issa. $\mathrm{Y}^{(\mathrm{a})}$, Ratrout. $\mathrm{N}^{(\mathrm{b})}$ \\ (a) (Civil Engineering Department, Fahd Bin Sultan University, Tabuk, Saudi Arabia, \\ (b) Civil Engineering Department, King Fahd University of Petroleum and Minerals, Dhahran, Saudi Arabia,
}

\begin{abstract}
Transport networks vary and change over time. This paper aims to contribute to raising the level of safety in the road transport industry (trucking industry), by assessing the current state of truck accidents, drivers, and regulations which control the land transport in Saudi Arabia. This has been conducted through surveys and field interviews with specialized authorities. Moreover, to evaluate the effectiveness of driving schools training programs, by interviewing students involved in such programs and with recent programs graduates. Results have indicated that the main reason for the decline of traffic safety is the lack of enforcing the law regulations. Other reasons for the decline were related to the drivers and driving schools. The comparison between truck accidents and other vehicles accidents showed that truck accidents were more serious. Some of the truck drivers' characteristics are the reasons that stand behind them making more accidents (such as low education level). Results also have indicated that driving schools doesn't increase students practical driving knowledge.
\end{abstract}

Keywords: Traffic Safety, Truck Accidents, land transport, driving schools.

\section{Introduction}

Transportation is an important factor in the social and economic development of a country. Among all of the transportation modes, land transportation is the most commonly used mode, especially for freight and other commercial activities. Injuries and deaths resulting from traffic accidents are a major and public health problem in all the world. In Saudi Arabia, the number of traffic accidents has reached a very high and alarming level, compared with other countries. On the other hand, truck accidents are more worst and results in more deaths and injuries if compared with accidents from the total vehicles types.

It is important to know that there is no truck accident data available in Saudi Arabia. That's why the data for this paper is collected from field through surveys and interviews with tucking companies and truck drivers through a national project, which aimed to assess the trucking industry, review of all local regulations concerned with safety, and suggest any enhancements in them to better the trucking safety. The main objective of this paper is to examine the rules and regulations which control the land transport in Saudi Arabia, through survey and field interviews with specialized authorities. These rules will be compared with other international regulations to identify any modifications needed to upgrade the Saudi regulations to the international standards.

\section{Background}

Globally, injuries and deaths resulting from traffic accidents are growing and cause public health problem. Based on World Health Organization (WHO 2013) report, number of deaths from traffic accidents exceed 1.24 million yearly. About $80 \%$ of these deaths are from middle income countries, with 20.1 deaths per 100 thousand population, even the registered vehicles in these countries only 52\%. According to WHO report, the economic cost of traffic accidents and injuries is estimated to be $1 \%$ of the gross national product (GNP) in low-income countries, $1.5 \%$ in middle-income countries and $2 \%$ in high-income countries. The global cost is estimated to be US\$ 518 billion per year. Low-income and middle-income countries account for US\$ 65 billion, which is more than the amount that they receive in development support.

In Saudi Arabia, the number of traffic accidents has reached a very high and alarming level which necessitates studying this problem extensively to find all possible solutions. According to statistics from the Ministry of Health in Saudi Arabia, road accident is the most common cause of death among humans. According to the traffic accident statistics in Saudi Arabia (Ministry of Interior 2011), the number of traffic accidents in 2011 is 544,179 accidents, the number of injuries is 39,160 and the number of deaths is 7,153.

The accidents rate in Saudi Arabia higher than most countries of the world such North America, South Korea, Thailand, Singapore and Japan (Al-Gamidi 1999 ). According to a study which estimates traffic accidents in Saudi Arabia, the number of deaths resulting from 544179 traffic accidents is 7153 deaths, represents $0.55 \%$ of the total deaths in the world, $2.1 \%$ in the Arab countries and $72.9 \%$ in GCC (Gulf Cooperation Council) countries. At this rate, the number of deaths per 100 traffic accidents is $1.3,18$ deaths per day or 0.76 deaths per hour. The number of injuries in Saudi Arabia, which is 39,160 , represents $0.1 \%$ of the total injuries in the world, 
$15.4 \%$ in Arab countries and $60.1 \%$ in GCC countries. At this rate, the number of injuries per 100 traffic accidents is 7.7 or 107 per day (Al-Saif 2012).

Table (I) below compare accident statistics between Saudi Arabia and other nations. It is important to mention that, these data were the newest available data from governmental sources that could be collected during the study time.

Table (I) Comparison between SA and Other Nations Accidents Statistics

\begin{tabular}{|c|c|c|c|c|}
\hline Country & $\begin{array}{c}\text { United States } \\
(2008)\end{array}$ & $\begin{array}{c}\text { UK } \\
(2009)\end{array}$ & $\begin{array}{c}\text { Australia } \\
(2010)\end{array}$ & $\begin{array}{c}\text { Saudi Arabia } \\
(2009)\end{array}$ \\
\hline Population & $304,375,000$ & $62,262,000$ & $22,151,900$ & $27,136,977$ \\
\hline Total Accidents & $10,200,000$ & 208,655 & NA & 484,805 \\
\hline Accidents per 1000 population & 34 & 3 & NA & 18 \\
\hline Total vehicle deaths within 1 year & 34,000 & 1,857 & 1,552 & 6,142 \\
\hline Traffic death per 100,000 registered vehicle & 14.5 & NA & 0.69 & 167.2 \\
\hline Death per 100,000 population & 12.3 & 3 & 7.02 & 22.6 \\
\hline
\end{tabular}

- Transport office, UK, 2009.

- $\quad$ Australian government, Accessed 2009.

In 1997, Severity Index reached 11.3 in Saudi Arabia compared to 1.2 only for Japan, and 4.6 for United Arab Imarets (Abu-Emah 2011). There are three causes of traffic accidents which are human factor, vehicle and road. Human factor is the main cause of accidents. While, it is at a rate of $60 \%$ to $80 \%$ in developing countries, it is $50 \%$ in industrialized countries (Al-Gamidi 1999).

Truck accidents in Saudi Arabia reach 738 accidents in 2009, producing about 107 deaths. A field study was conducted in Saudi Arabia to assess truck drivers awareness of the correct procedure for selecting and maintaining tires on their trucks, the study concluded that truck drivers need appropriate instruction on how to select, use, and maintain tires in order to reduce traffic accidents resulting from tire failure, the study also indicated that trucks accounted $11 \%$ of all vehicles involved in traffic accidents, and about $13 \%$ of these accidents resulted from tire failure, with $3.7 \%$ for truck accidents (Ratrout 2003). Moreover, human factors in driving are composed of two components which are driving skill and driving style (Türker 2006). (Smith 2001) gave a wider explanation of the driving task and split it into two categories which are Basic driving skills, and Safe driving skills.

Work-related drivers are those who drive at least once a week for work-related purposes such as truck drivers (Haworth et al. 2000). According to a study in Australia, work-related drivers reported higher crash involvement rates in their work vehicles than their own vehicles, even after controlling the kilometers driven (Newnam et al. 2002). Besides that, the available statistics in the United States, work-related drivers accounted for the highest number of fatal work injuries from a total of 4547 work-related fatalities, 968 were traffic accidents (Bureau of Labor Statistics 2010).

Drivers' education in the early stage was only the basic instructions that the new owners needed to use their vehicles (Daniel 2012). Due to the increased number of traffic accidents, driver education became as society-regulates activity that has potentials to increase traffic safety (Esko 2011). According to a study in Saudi Arabia, it was found that driving school has a significant impact on improving the knowledge of the student on traffic rules and traffic signs, but its impact on improving driving skills is limited (Ratrout 1997).

According to a study on the Driving Schools Programs and their role in raising traffic awareness in Saudi Arabia, it was found that there are some errors in these programs because these programs do not affect the behavior of drivers in order to improve their defensive driving and not to commit driving mistakes which lead them to be involved in accidents (Al-Hazah 2004). A study proved the need for night restriction for reducing the risk of fatal accidents for new driver (McCartt 2003). Also, it was found that each additional hour of night restriction reduced the fatal crash rate.

\section{Methodology}

This paper studies and reviews the existing national and international studies related to trucking safety. And comparing trucks accidents statistics and trucks drivers with other vehicle types. In this study an interviews were conducted with local concern partners (governmental and local), to better understand the current situation of trucking industry. On the other hand, field data were collected through surveys and interviews with tucking companies and truck drivers.

The study is mainly focusing in the three main regions in Saudi Arabia which are: the North Eastern Province (Dammam City), the South Western Province (Jedah City) and the Central Province (Riyadh City) and the main road connecting them. The reason for selecting these three regions is that it considered the largest in 
size and the highest in population, in addition to that, traffic accidents in these regions account more than $78 \%$ of the total accidents in Saudi Arabia.

The survey was distributed to the main trucking companies in the three regions, around hundred survey were collected from truck companies and 74 from buses companies. The survey include questions mainly related to activity type that the companies conduct, working policies (insurance, required papers, safety equipments), their opinions and recommendations to improve trucking industry safety, drivers (qualification, ages, nationalities, accidents involvement, and health tests), and trucks conditions and maintenance.

Field interviews were also conducted in the same time in weighting stations in the main roads with more than 450 truck drivers. Generally, the interview was related to the main issues mentioned in the survey, to complete any additional information and to check the reliability of survey data.

\section{Results}

The results from both survey or interviews are approximate similar with few differences which didn't affect the study results. Interview results were adopted if difference occurred. The comparison between truck accidents with other vehicles accidents showed the high risk of truck. Also truck drivers have certain characteristics differ from others. More detailed results are shown in sections below.

\subsection{Truck Accidents}

Truck accidents are more worst and results in more deaths and injuries if compared with accidents from the total vehicles types. A comparison between truck accident statistics with the statistics of total accidents in Saudi Arabia in 2009 are shown in tables II and III below.

Table (II) Comparison between Injuries and Fatalities rates for Truck along rural roads and All Accidents in $S A$ (2009)

\begin{tabular}{|c|c|c|}
\hline Number & Truck accidents $^{\text {a }}$ & Total accidents $^{\mathbf{b}^{\prime}}$ \\
\hline Accidents & 738 & 484,067 \\
\hline Number of Injuries (person) & 469 & 34136 \\
\hline Deaths (persons) & 107 & 7035 \\
\hline Injuries (per 1000 accident) & 636 & 12.5 \\
\hline deaths(per 1000 accident) & 145 & 78.9 \\
\hline Risk index & 6.9 & (one death/79 accidents) \\
\hline
\end{tabular}

Note: Total accidents include all vehicle accidents except truck accidents.

a: Road security special forces, 2010

b: Ministry of Interior Statistical Report for traffic accidents, 2010

Table (III) Comparison between truck accidents and all accident in SA in terms of severity

\begin{tabular}{|c|c|c|}
\hline Accident severity & Truck accidents $^{\mathbf{a}}$ & Accidents of all types of vehicles $^{\mathbf{b}}$ \\
\hline Property damage only & $22 \%$ & $94 \%$ \\
\hline Injuries and deaths & $78 \%$ & $6 \%$ \\
\hline
\end{tabular}

Note: All types of vehicles include passenger cars and trucks.

a: Ratrout. $\mathrm{N}$ et. al, 2010

b: Ministry of Interior Statistical Report for traffic accidents 2010

The above table showed that number and percentage of deaths and injuries per truck accidents are much more than that from all vehicle accidents. This clearly indicate the high risk of heavy vehicles accidents and their related loses. Also the difference in deaths also clearly appeared in the risk index where only one death occurred in around 79 accidents produced from all types of vehicles compared to one death at every 7 heavy vehicle accidents. Death opportunities in heavy vehicles accidents is 11 times that from all types of vehicles accidents. Tables IV,V, and VI below present a comparison between truck accidents characteristics and characteristics of all types of vehicles accidents.

Table (IV) Comparison between truck accidents and all accident in SA in terms of accidents causes

\begin{tabular}{|c|c|c|}
\hline Accident cause & Truck accidents $^{\mathbf{a}}$ & Accidents of all types of vehicles $^{\mathbf{b}}$ \\
\hline Human (Driver) & $70 \%$ & $76 \%$ \\
\hline Road \& Vehicle & $30 \%$ & $24 \%$ \\
\hline
\end{tabular}

a: Ratrout. $\mathrm{N}$ et. al, 2010

b: Ministry of Interior Statistical Report for traffic accidents 2010 
Table (V) Comparison between truck accidents and all accident in SA in terms of time of accidents

\begin{tabular}{|c|c|c|}
\hline Accident time & Truck accidents $^{\mathrm{a}}$ & Accidents of all types of vehicles $^{\mathrm{b}}$ \\
\hline Day & $52 \%$ & $57 \%$ \\
\hline Night & $48 \%$ & $43 \%$ \\
\hline
\end{tabular}

a: Ratrout. $\mathrm{N}$ et. al, 2010

b: Ministry of Interior Statistical Report for traffic accidents 2010

Table (VI) Comparison between truck accidents and all accident in SA in terms of accidents locations

\begin{tabular}{|c|c|c|}
\hline Accident location & Truck accidents $^{\text {a }}$ & Accidents of all types of vehicles $^{\text {b }}$ \\
\hline Inside cities & $68 \%$ & $85 \%$ \\
\hline Outside cities & $32 \%$ & $15 \%$ \\
\hline
\end{tabular}

a: Ratrout. N et. al, 2010

b: Ministry of Interior Statistical Report for traffic accidents 2010

The difference in percentages in the above tables are statistically tested using chi-square. The results indicate that there were no statistical difference between truck and all vehicles accidents in terms of time and cause of accident. On the other hand the difference clearly appeared in terms of accident location and severity.

\subsection{Truck Drivers}

Truck drivers differ from non-professional drivers in many respects, such as higher annual mileage, longer working hours, and more demanding driving tasks. Truck drivers are more exposed to traffic for long hours, which may make them more exposed to fatigue and aggression. After many years of professional driving (such as truck drivers), drivers seem to develop higher mastery of both vehicle and road use and therefore allow themselves to take more risks. In case of accidents while working, professional drivers have the highest rate of accidents compared to other drivers.

Truck drivers are involved excessively in high number of traffic accidents. Speeding is the most aberrant driving behavior of truck drivers which leads them to the involved in accidents. The two most frequent errors associated with truck drivers are hitting objects or someone while reversing that could not been seen previously due to the blind spots of truck drivers and almost hitting a cyclist coming up on turning left. Failure to detect rules of intersections, non-adaptive speed and changing lanes with incorrect maneuvers are the most common causes of accidents between trucks and other vehicles.

The field observation on truck drivers presented in this paper include their age and relation to accidents, in addition to other characteristics of truck drivers such as (education level, driving experience, working hours, understanding Arabic or English language). Age distribution of truck drivers and drivers of all type of vehicles involved in accidents are shown in figure I below.

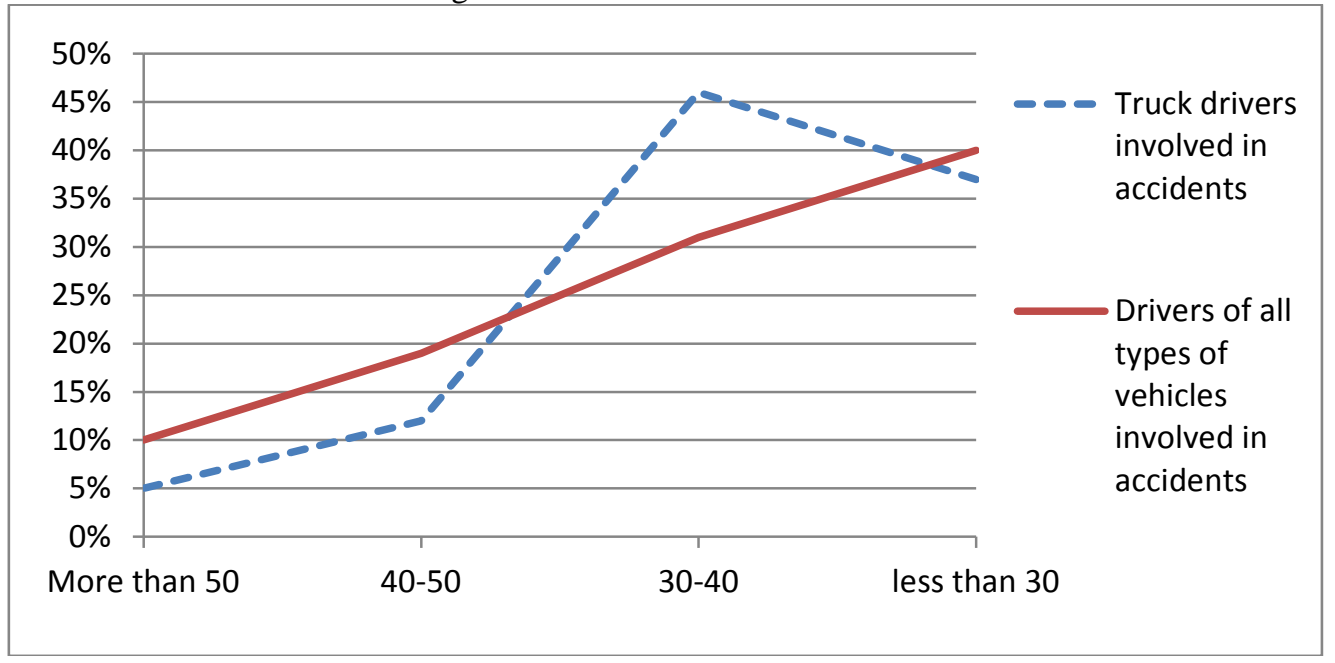

Figure I: Age distribution of truck drivers and drivers of all type of vehicles involved in accidents A comparison between characteristics of truck drivers involved in accident with these characteristics of drivers of all types of vehicles are shown in tables VII and VIII below.

Table (VII) Educational level distribution of Accidents Involved Drivers

\begin{tabular}{|c|c|c|}
\hline Educational level & Truck drivers ${ }^{\mathbf{a}}$ & $\begin{array}{c}\text { Drivers of all types of vehicles involved } \\
\text { in accidents }^{\mathbf{b}}\end{array}$ \\
\hline Non- educated & $19 \%$ & $9 \%$ \\
\hline Educated & $81 \%$ & $91 \%$ \\
\hline a: Ratrout. N et. al, 2010 & & \\
\hline
\end{tabular}


b: Ministry of Interior Statistical Report for traffic accidents 2010

Table (VIII) Languages Understanding of Accidents Involved Drivers.

\begin{tabular}{|c|c|c|}
\hline Language & Truck drivers $^{\mathbf{a}}$ & $\begin{array}{c}\text { Drivers of all types of vehicles involved } \\
\text { in accidents }^{\mathbf{b}}\end{array}$ \\
\hline Reading \& Understanding Arabic & $29 \%$ & $65 \%$ \\
\hline Reading \& Understanding English & $23 \%$ & $82 \%$ \\
\hline
\end{tabular}

a: Ratrout. N et. al, 2010

b: Ratrout. N et. al, 2012

It was appeared from above tables that about $19 \%$ of truck drivers interviewed are non-educated drivers. Around $29 \%$ can read and understand Arabic words, and about $23 \%$ can read and understand English words. The average driving experience for the interviewed truck drivers exceed 7 years, with 9 working hours daily.

The difference in percentages in the above tables are statistically tested using chi-square. The results indicate that the difference is statistically significant between the mentioned truck driver characteristics and the characteristics of all type of vehicles. Statistical analysis also indicated that chuffers (such as truck drivers) not involved in accidents have higher correct answers about traffic knowledge and regulations than those involved in accidents. Chuffers whom responsible on deaths or injuries have the worst answers in similar questions. Truck drivers answers were the worst compared to small vehicle drivers. Trucking companies also have been interviewed to analyze certain drivers characteristics. Drivers age distribution in the interviewed trucking companies and their involvement in accidents are shown in table IX below.

Table (IX) Truck drivers age distribution and their percent of accidents involvement during 2010

\begin{tabular}{|c|c|c|}
\hline Age distribution & $\begin{array}{c}\text { Drivers Distribution in the trucking } \\
\text { companies interviewed }\end{array}$ & $\begin{array}{c}\text { Percent of drivers involved in accidents in } \\
\text { the trucking companies interviewed }\end{array}$ \\
\hline less than 26 & $5 \%$ & $4 \%$ \\
\hline $26-30$ & $18 \%$ & $33 \%$ \\
\hline $31-35$ & $25 \%$ & $27 \%$ \\
\hline $36-40$ & $22 \%$ & $19 \%$ \\
\hline $41-45$ & $19 \%$ & $7 \%$ \\
\hline $46-50$ & $7 \%$ & $5 \%$ \\
\hline $51-55$ & $3 \%$ & $3 \%$ \\
\hline $56-60$ & $1 \%$ & $2 \%$ \\
\hline total & 100 & $100 \%$ \\
\hline
\end{tabular}

Ratrout. N et. al, 2010

\section{Driving education and driving schools in Saudi Arabia}

Driving schools play an important side in educating students the right and safe driving procedure. The students are required to pass the vision, written and practical tests to obtain a driving license. The written test is on traffic rules, road signs, and principles of traffic safety. The practical driving test gives the student the opportunity to prove his ability to drive safely with the traffic officer. When the student needs to take the written test, he can take this test in any of the eleven languages which are Arabic, English, Indian, Indian Kerala, Bengali, Turkish, Urdu, Sri Lanka Tamil, Sri Lanka Sinhalese, Filipino and Indonesia. Currently, the practical test is conducted inside the driving school.

According to some local studies the driving schools didn't provide the students with a proper needed ability to drive in the field, in addition to its weak training programs for trucks. Because of that, an interviews were conducted between students just involved to the schools and other just graduate from it to compare the difference in their response to general thirty driving related questions.

About $54 \%$ of the students involved in driving schools can read and understand Arabic signs, $70 \%$ can read and understand English signs. While $65 \%$ of the graduated students can read and understand Arabic signs, $80 \%$ can read and understand English signs. The two groups correct answers about certain driving related question (such as tire pressure, speed limit inside city), traffic signs (such as pedestrian crossing) and about directions at intersection were very low.

The concept based on testing if there is a difference in the mean of scores before enrollment and after graduation for driving schools. This test is needed to check the effectiveness of performance of driving schools in delivering traffic knowledge by using 2 t-sample tests at $90 \%$ confidence. It is based on assumption that the mean of scores before enrollment to driving school is less than the mean of scores after graduation. The result indicated in table $\mathrm{X}$ below. 


\section{Table $(X)$ mean of scores before enrollment and after graduation for driving schools}

Two sample test

Status

Before enrollment

After graduation

$\begin{array}{cc}\text { mean } & \text { standard deviation } \\ 17.38 & 3.81 \\ 17.92 & 3.78\end{array}$

3.81
3.78

$\mathrm{T}-$ value $=-2.24 \quad \mathrm{P}$-value $=0.013$

Since the P-value $=0.013$ which is less than 0.1 , this indicate that there difference between the two students groups is significant. And the answers of after graduation students is higher with 0.54 (1.67\%) than those answers from before enrollment students. But this difference is too much low from practical point view, and indicate that driving schools didn't increase students driving knowledge practically.

Statistical tests also conducted to measure the difference in certain students personal characteristics with their answers. It was appeared that as educational level increase the correct answers increase, with a difference reach to $20 \%$ between collage educated and non-educated drivers. Also it was appeared from statistical tests that as driver ability to read and understand Arabic or English words he his correct answers increase.

\section{Trucking regulation}

The current trucking regulation in the Kingdom will be reviewed, these regulation will include certain criteria for truck driver, truck as a vehicle, cargo, and trucking companies.

Table (XI) Trucking regulations existence and enforcement in Saudi Arabia

\begin{tabular}{|c|c|c|c|c|}
\hline \multicolumn{2}{|c|}{ Category/Regulation } & Exist & Adequate & Enforced \\
\hline \multirow{5}{*}{ Driver } & Diseases check & Yes & No & No \\
\hline & Alcohol check & Not applicable & Not applicable & Not applicable \\
\hline & Age $(25-60)$ & Yes & Yes & No \\
\hline & Language (Arabic or English) & Yes & Yes & No \\
\hline & Continuous Driving hours (4 hrs.) & Yes & No & No \\
\hline \multirow[t]{4}{*}{ Truck } & Registration Validity (3 years) & Yes & No & Yes \\
\hline & Weight and dimension regulations & Yes & Yes & No \\
\hline & Maintenance check & Yes & No & No \\
\hline & $\begin{array}{l}\text { Existence of fire extinguisher, first aid, } \\
\text { communication device, }\end{array}$ & Yes & Yes & No \\
\hline \multirow[t]{2}{*}{ Cargo } & Weight and dimension regulations & Yes & Yes & No \\
\hline & Driver check the cargo & Yes & No & No \\
\hline \multirow[t]{3}{*}{ Company } & Safety follow up & No & No & Unknown \\
\hline & Driver accidents record & No & No & Unknown \\
\hline & Driver personal record during service & No & No & Unknown \\
\hline
\end{tabular}

"Adequate" is referenced to what is applied generally in the USA.

It is appeared that there are weak application of the specifications in current trucking situation. Enforcement of trucking regulation are not applicable. Trucking companies regulations are not exist. Drivers diseases check, driving hours, and truck maintenance check are not adequate.

\section{Probable Causes of Truck Accidents in Saudi Arabia}

1- Lake of enforcement, making drivers and companies avoid following regulations and laws.

2- Factors related to drivers, such as communication problems, lack of education and experience.

3- Factors related to driving schools programs and training system adopted in such schools

4- Lake of services and corporation between governmental and local authorities.

\section{Results and Conclusion}

From the above details it is clear that accidents situation in the Kingdom is worst than other countries since it results in more deaths and injuries. Accident types was mainly property damage only with (95\%). Human errors were the main accident causes with $75 \%$, followed by vehicle deficiencies with $20 \%$. Trucks accidents are more worst if compared with accidents from the total vehicles types. It was statistically proved that truck drivers involved in traffic accidents more than the expected numbers. Weak and not enforced regulation related to trucking industry which include drivers and there response to law, trucks and its condition, and the companies. It's also appears that driving schools didn't increase the driving knowledge to the students, and there is no special training for the heavy vehicles drivers.

The driving manual in Saudi Arabia is very weak and all the information is general and does not focus on what the driver should do when facing any situation while driving. The manual should focus more on change of behaviors of the drivers by presenting more information about the an expected situations that the drivers may face in real life. The driving manual should instruct the learner drivers the right way of driving and they should 
not be allowed to face unexpected situations in the real life without any preparations. These instructions should be complete, descriptive and up to the date. Driving schools in Saudi Arabia must be equipped with training field, at least three kinds of training vehicles of different sizes, driving simulator for training purposes, instructors should be qualified from certified scientific institutes with experience of at least one year. the practical test should be conducted outside the school.

\section{References}

[1]. Abu-Emah, A. (2011). Indicators of traffic data and traffic information, King Abdul Aziz City for Science and Technology. National strategic plan for traffic safety. The current traffic situation.

[2]. Al-Gamidi, A. (1999). Traffic accidents in Saudi Arabia: Causes, effects and solutions. National Committee for Traffic Safety.

[3]. Al-Hazah, A.(2004). Driving Schools Programs and its role in increasing awareness of the traffic, Naif Arab University for Security Sciences, Saudi Arabia.

[4]. Al-Saif, A. (2012). Estimation of traffic accidents in the GCC countries and ways to address them in Saudi Arabia, The first forum for traffic safety, "the Saudi Society for Traffic Safety, Dammam, Saudi Arabia".

[5]. Bureau of Labor Statistics. (2010). Fatal Workplace Injuries in 2006: A Collection of Data and Analysis, USA.

[6]. Danial, M. (2012). Presentation: Origins of and Rationale for Minimum Licensing Age Laws, HUMAN FACTORS WORKSHOP 144E, TRB. ANNUAL MEETING, Sunday, January 22, 2012.

[7]. Department of Infrastructure, Transport, Regional Development and Local Government. (Accessed November 2009). Australian government. www.infrastructure.gov.au/department/about/about.aspx

[8]. Directorate General of Traffic. (2010). Statistical Report for traffic accidents, Ministry of Interior, Saudi Arabia.

[9]. Esko, K. and Kati, H. (2011). "Driver Education and Training" Handbook of Traffic Psychology. By Bryan E. Porter. $389-399$. ELSEVIER.

[10]. Haworth, N., Tingvall, V., Kowadlo, N. (2000). Review of Best Practice Fleet Safety Initiatives in the Corporate and/or Business Environment, Report No. 166, Monash University Accident Research Centre, Melbourne.

[11]. McCartt, T., Shabanova, I., \& Leaf, A. (2003). Driving experience, crashes, and teenage beginning drivers. Accident Analysis \& Prevention, 35, 311-320.

[12]. Newnam, S., Watson, B., Murray, W. (2002). A comparison of the factors influencing work-related drivers in a work and personal vehicle. In: Proceedings of the Road Safety Policy, Education and Policing Conference, Adelaide, Australia

[13]. Ratrout, N. (1997). "Test Score Before and After Driving School Attendance in Dammam",AJSE, Volume 22,Number 2B.

[14]. Ratrout, N. (2003). "Truck Drivers' Practice in Maintaining Tires in Saudi Arabia", Al-Azhar Engineering 7th International Conference, Cairo.

[15]. Ratrout. $N$ et. al. (2010). Safety in road transport between cities in Saudi Arabia, sponsored by King Abdullah City for Science and Technology, Saudi Arabia.

[16]. Ratrout. N et. al. (2012). Characteristics of expatriate chauffeurs and their relation on traffic accidents, sponsored by King Abdullah City for Science and Technology, Saudi Arabia.

[17]. Road security special forces. (2010). Trucks and Buses Accidents, Ministry of Interior, Saudi Arabia.

[18]. Smith, F. (2001). Safety needs of novice drivers: driver factors. In Driver Education at the Crossroads. Proceedings from the Committee on Operator Education and Regulation (Report No. E-C024), Transportation Research Circular. Washington, D.C.: Transportation Research Board.

[19]. Statistical Department of the Directorate General of Traffic. (2011). Ministry of Interior, Saudi Arabia.

[20]. Turker, O., Timo, L., Joannes, C., Dianne, P., and Heikki, S. (2006). Cross-cultural differences in driving skills: A comparison of six countries, Accident Analysis and Prevention 38, 1011-1018.

[21]. United Kingdom Transport Office. (2009). URL: http: //www.transportoffice.gov.uk/

[22]. World Health Organization (WHO). (2013). World Report on Road Traffic Injury Prevention, Geneva. 